\title{
RAZINSKY Hili, Ambivalence. A Philosophical Exploration
}

London-New York, Rowman \& Littlefield, 2017, p. ix, 285

\section{Guido Baggio}

\section{QpenEdition \\ 1 Journals}

\section{Electronic version}

URL: http://journals.openedition.org/ejpap/1736

DOI: $10.4000 /$ ejpap. 1736

ISSN: 2036-4091

\section{Publisher}

Associazione Pragma

\section{Electronic reference}

Guido Baggio, « Razinsky Hili, Ambivalence. A Philosophical Exploration», European Journal of Pragmatism and American Philosophy [Online], XI-2 | 2019, Online since 24 December 2019, connection on 23 September 2020. URL : http://journals.openedition.org/ejpap/1736 ; DOI : https://doi.org/10.4000/ ejpap. 1736

This text was automatically generated on 23 September 2020 .

\section{(i) $(9$}

Author retains copyright and grants the European Journal of Pragmatism and American Philosophy right of first publication with the work simultaneously licensed under a Creative Commons AttributionNonCommercial-NoDerivatives 4.0 International License. 


\title{
RAZINSKY Hili, Ambivalence. A Philosophical Exploration
}

\author{
London-New York, Rowman \& Littlefield, 2017, p. ix, 285
}

\section{Guido Baggio}

\section{REFERENCES}

RAZINSKY Hili, Ambivalence. A Philosophical Exploration, London-New York, Rowman \& Littlefield, 2017, p. ix, 285

1 Hili Razinsky's book aims to investigate the philosophical notion of ambivalence and to support an anti-irrationalist, non-contradictory, and anti-dichotomic perspective of this notion. The book is hardly ascribable to an explicit philosophical tradition: it includes references to both continental and analytic philosophers (from Heidegger, Husserl, and Sartre, to Davidson and Freud, among many others). Razinsky also offers examples taken from literary works to corroborate her replies to the following questions: what is ambivalence? What character does it assume? How is ambivalence to be understood? Is it rational or irrational? How is ambivalence expressed, and how is it recognized?

2 The volume consists of nine chapters divided into three parts. Chapters 4, 5, 8, and 9 are partial or total re-workings of previous articles by the same author. The appendix chapter is a discussion of the distinction between "inherent ambivalence" and "contingent ambivalence."

3 The first chapter is essential for the reader to attain an overview of the ambivalence issue. Razinsky provides a general definition of ambivalence involving key concepts such as intentionality, attitude, mind, and rationality. All over the book, these same concepts are alternatively focused upon to show the main philosophical perspectives on ambivalence. 
Razinsky's definition of ambivalence refers to the mental and behavioral attitudes of human beings. According to the author, an ambivalent person is a person who "holds two opposed mental attitudes toward one and the same object" (p. 16). However, maintaining two opposing attitudes is not necessarily the expression of a split subject; this condition, instead, means that the subject herself is ambivalent in the sense that she expresses a plurality in the unity of her being. This interpretation intentionally prevents us from considering ambivalence as an irrational character of the subject as something that goes against schemes of rationality and coherence. Ambivalence is not a contradictory phenomenon, as Razinsky wishes to stress as early as in the introduction: "The main thought behind this book is that if human lives are in fact often ambivalent, this may be conceived as an invitation to rethink our notions of personhood and rationality, as well as those of mental attitude, desire, judgment, emotion, action, and consciousness." (4).

5 This book aims to rethink acquired notions through an overall study of ambivalence. The latter is unconventionally understood as a side of subjectivity, that is, of a "psychophysical creature and by the same token a subject - the subject is a person" (28). On this point, the question that Razinsky's book poses concerns both concepts of subjectivity and person. These concepts are taken up by the author in an instrumental way to develop her thesis of the ambivalent character of human existence. However, in contrast to her main thought to rethinking notions, these concepts turn out to be rather unexplored or too simplified. The author justifies with the scope of the book her choice not to problematize the subject/person distinction. She intends to address the main features of ambivalence specifically. However, to dismiss these notions with a footnote seems a bit too limited all the more that ambivalent persons and their mental and behavioral attitudes are constantly addressed. This lack of deepening also affects other notions frequently utilized by the author, such as intention, attitudes, and mental attitudes. As Razinsky argues, her understanding of intentionality is in line with the conceptions of Davidson and Husserl. In particular, intentionality means the manifestation of a person's subjectivity (21). The example Razinsky uses is that of someone who loves someone else or who does something. To love and to do something are two intentional aspects of human life, and this means that the person intends to love or intends to do that thing. "If a cluster of thoughts, actions, and so on has the meaning of a certain attitude of love, it is the person herself who 'means' it as such, and it is from her point of view that this cluster takes the direction of love or constitutes a tendency that is love." (21). So that mental attitudes and actions, as well as many other mental and behavioral aspects, are intentional.

$6 \quad$ As the author further specifies, the book deals mainly with mental attitudes. But what are mental attitudes, or even, as Razinsky simplifies, what are attitudes? An attitude, she argues, is "a disposition to behavior and consciousness" (22). According to the author, a disposition implies an outlook, and this shows its intentional character, as it is towards something or someone (22). Moreover, attitudes are not necessarily acknowledged. They are constituted together with their behavioral and conscious expressions. However, attitudes, behavior, and other engagements "which are not at the particular time experienced as these attitudes or behavior" are distinct from "thoughts, conscious actions, conscious attitudes" (29-30). In a nutshell, attitudes are intentional dispositions conscious or unconscious, towards something or someone. The adjective mental used for attitudes seems to have an extremely generic value because 
the intentionality that characterizes attitudes implies basic rationality that connects attitudes to the mental interconnections of the subject. In this perspective, the subject is a creature engaged in "multiple ways." "The sense in human life is hence bound with a soft identity of mental attitudes, which is to say that while a person's attitude is in a sense defined by its interlinkages with behavior and consciousness, further attitudes, and other engagements, it also transcends any definition and is essentially open to redefinition." (24).

7 The author defines the mind as "the person's array of mental attitudes, [which] captures a focal part of the person's intentionality" (25). Here again, the adjective mental seems to be used too vaguely. On the one hand, the realm of the mind is not reducible to intentionality, and therefore to mental attitudes; while on the other hand, it is attributed to the character dispositions as well as to other aspects that constitute the "matter-of-course background" of the subject's engagements.

8 The second chapter is programmatic for the author presents three clusters of philosophical issues concerning ambivalence she will be dealing with in the following chapters. The first cluster concerns the thesis that ambivalence is not possible because it implies the idea of a person with two opposing attitudes. Addressing this philosophical problem, the author compares her approach to ambivalence with the multiplicity approach proposed by Harry Frankfurt in The Faintest Passion (1992), and with Davidson's conception of personhood as a matter of basic rationality. The multiplicity approach can either means that the subject is a subject only until she becomes ambivalent, or that she is essentially a plural creature. In this perspective, in both cases, ambivalence is not compatible with the idea of a unitary subject. Frankfurt adopts the first meaning, considering ambivalence as the annihilation of the subject. In Davidson's perspective, instead, mental unity consists of "the rational interrelation and consistency of attitudes" (39). Davidson speaks of two quasi-subjects to frame contrasting or inconsistent attitudes of a person. According to Frankfurt and Davidson, the mental unity of subjects requires a minimum level of consistency. This hypothesis is problematic to the author, for she maintains that ambivalence involves both unity and multiplicity at the same time. As Razinsky will explain better in chapter 7, ambivalence involves basic rationality and a unitary subject. However, even if the unitary subjects have a plurality of attitudes, these attitudes do not divide the subject into quasi-subjects, nor do they confer an irrational character to ambivalence. Subjects cope daily with contrasting attitudes that characterize their personalities (see 174-87).

9 As for the second philosophical problem, which is the idea that ambivalent behavior makes people incapable of acting, the author believes that from mutually exclusive behaviors and desires it does not follow that ambivalent behavior is the combination of two conflicting practical conclusions, but only that: "ambivalence is a challenge for our conduct-one to which we respond in all sort of resourceful ways. [...] Ambivalence often involves creative compromise behavior that forms an ambivalent yet substantial direction in the person's life. Ambivalence allows for compromise action, in which we jointly fulfill both opposed desires." $(49,51)$.

10 The second part of the book goes from chapter 3 to 6. In this section, Razinsky examines the relationships between emotional ambivalence and the notions of subjectivity and agency. She supports an idea of a person as unity in plurality and considers ambivalence as a central feature of mental unity (chapter 3). Then the author devotes herself to the analysis of ambivalence from a behavioral perspective. According 
to her, emotional ambivalence constitutes: "a wider complex that cannot be reduced to two independent emotional complexes" (61). Her definition of emotional ambivalence relies on Philip J. Koch's article "Emotional Ambivalence" (1987). According to Koch, emotions are complexes of bodily feelings, attentional sets, evaluations/judgments, and desires/impulses/inclinations to behave. In other words, emotions are everything that can fit into an opposition situation. Razinsky integrates Koch's conception of emotions with the feature of intentionality: emotions are understood as "mental attitudes toward objects" (63). Thus, she can speak of a unity in plurality that consists of keeping together conflicting emotions with other mental interlinkages. Such unity in plurality is circumscribed, however, by the "phenomena and language of ambivalence and of the mind" (67), that is to say, "it is in terms of interlinkages involved in the ambivalence that particular instances can be understood and that levels and aspects of integration can be described" (76).

11 The author adopts a very naïve notion of subjectivity that includes the idea of unity in plurality together with a basic understanding of the human being as a unitary subject. At the same time, however, Razinsky also states that this notion of subjectivity is not sufficient to sustain the idea of unity in plurality, because unity is "neither simple nor quasi-simple." Therefore, "to take the human being or mind for a simple unity is tantamount to denying ambivalence" (67).

12 At this point, Razinsky introduces the concept of engagement to try to make her idea of ambivalence succeed. Engagement is defined in a footnote as "the concrete manifestations of subjectivity or as the intentional aspects of a person's life" (77), and it includes "attitudes, thoughts, sensations, acts, and other mental elements (behavior included)" (67). She then offers an implemented definition of ambivalence that includes the subject's plurality of engagements. This definition applies to the mind understood in terms of the totality of engagements, or totality of attitudes. Although the same phenomenon of ambivalence "implies a cognitive relevance" (70), however, the author strategically uses again the concept of mind to hold together heterogeneous elements without providing a sufficient analysis of it. She just refers to the Davidsonian notion of mental holism, comparing the idea of unity in plurality with what Davidson calls "the person's engagements as basically or constitutively rational" (68).

In chapter 5, the author addresses the theme of conscious subjectivity. She states that the term consciousness refers in her book "to more or less momentary consciousness or to particular aspects of such moments" (99). In a footnote, she specifies that momentary is to be intended as "more or less momentary," or rather what is called "the specious present" (125). This is a too hasty way to solve the complex issue of consciousness, even more so by invoking the notion of "specious present," which constitutes a problematic issue itself. The author uses this extremely general definition of consciousness to refer to the way in which momentary consciousness takes time as part of an "ongoing consciousness," in order to argue that "intentional experiences and intentional aspects of experience would be conscious engagements or aspects of a consciousness differentiated as to how the consciousness goes out" (115).

Chapters 6 and 7 are dedicated respectively to Razinsky's comparison between the concept of unity in plurality and the concepts of harmonious unity and harmonization - in this regard, she refers to Freud's notion of personhood; to the issue of selfdeception and ambivalent beliefs. In the last two chapters, the author finally responds to the idea of the impossibility of ambivalence concerning the notions of truth and 
value, which represents the third cluster of philosophical problems introduced in chapter 2.

Razinsky's attempt to maintain an anti-reductionist approach to the complex phenomenon of ambivalence is undoubtedly interesting. Her effort to distinguish the phenomenon of ambivalence from its logical interpretation, which identifies ambivalence with self-contradiction, is appreciable. This distinction is highlighted in chapter 4 , dedicated to ambivalent behavior. The author tries to illustrate that the conflict between opposing behavioral inclinations does not imply contradictory desires, but rather there is a vagueness that accompanies ambivalence. However, once again, a problematic notion such as vagueness is not adequately investigated.

Reading this book gives the impression that the promising intentions of the author have turned out to be more complicated than expected in their realization, which is perhaps the reason why it is not fully successful. Razinsky's attempt to preserve the complexity of the phenomenon of ambivalence leads the author to persist on a very general level of reflection with respect to the multiple dimensions involved in the human phenomenon of ambivalence. The book would have been much more interesting if the author had shown a greater sensitivity to the problematization of concepts. The unproblematic way in which she accepts concepts conflicts with her insisting on the need of a complex theoretical framework to any consistent discussion on ambivalence. The conceptual problematization would have made Razinsky's book a relevant contribution to the debate on ambivalence. But unfortunately, this was not the case. A number of the key concepts used to discuss ambivalence would have required much more in-depth work, in particular, the notions of mind, emotion, engagement, vagueness (attributed to behavior (86)), and consciousness. Razinsky admits that some definitions of the concepts she currently uses are not sufficient to describe ambivalence, but she keeps adopting them in order to avoid deviating from her main focus. In conclusion, although the author's intention is remarkable, the book does not fully satisfy the reader who wants to get an idea of the phenomenon of ambivalence and of the complexity of the human aspects it involves.

\section{AUTHORS}

\section{GUIDO BAGGIO}

Università Roma Tre

guido.baggio[at]uniroma3.it 